\title{
Characteristics of Meiosis in Some Winter Barley Varieties
}

\author{
J. Stoinova \\ Acad. D. Kostov Institute of Genetics, 1113 Sofia, Bulgaria
}

Accepted October 7, 1994

Studies of meiosis in different varieties of barley are rather scarce and related mainly to the duration of this process. According to Lindgren et al. (1969) the total duration of meiosis from pachytene to telophase II is not more than 3 days, while the shortest stages are not longer than $1 \mathrm{hr}$.

Bennett and Finch (1971) are of the opinion that the total duration of meiosis is less-a day and a half approximately. As the longest stage the authors consider the leptotene $-12 \mathrm{hr}$; the period of pachytene, zygotene and telophase II is from 8 to $9 \mathrm{hr}$ and metaphase I, telophase I and metaphase II last from $1.2 \mathrm{hr}$ to $2 \mathrm{hr}$. All the other stages are shorter than an hour.

The duration of meiosis has been established more precisely by Finch and Bennett (1972) in diploid and tetraploid barley varieties. For the diploid variety it is about $39 \mathrm{hr}$ and for the tetraploid-about $31 \mathrm{hr}$. In both genotypes each stage of meiotic division runs in approximately equal relations as to the total duration of meiosis compared to that of other cereals.

Meiotic division of pollen mother cell is completed prior to the onset of the ear formation phase. As per data from Ekberg and Eriksson (1965) the first mitotic division in pollen grains is found shortly before the appearance of awns, while the second one takes place when the awns are at the height of $25 \mathrm{~mm}$ aproximately above the sheathing leaf.

Other authors investigated meiosis in tetraploid varieties of barley in relation to floret fertility and yield. Reinbergs et al. (1970) established that fertility was highly variable-2.7\% in Montcalm variety and over $48 \%$ in York variety at approximately the same number of quadrivalents per cell. The reason for variation in fertility is considered to be the different orientation of chromosomes in the quadrivalent association and their division in anaphase $\mathbf{I}$. Tetraploid varieties of best fertility have the highest percentage of cells with division of chromosomes $14-14$ in anaphase $\mathrm{I}$.

The investigations of Fedak (1975) corroborate the conclusion concerning the missing relationship between the number of quadrivalents per cell and the fertility and the existing correlation between the frequency of cells with chromosomes division $14-14$ and the higher fertility.

Evans and Rahman (1990) used the term "efficient cells" to characterize cells which did not contain univalents or trivalent associations in metaphase I. It is established that the correlation between the quantity of "efficient cells" and cells with chromosome division 14-14 in anaphase $I$ is not clearly marked.

This work treats the studies of the meiotic process in diploid barley varietis and the configuration of bivalents is detailed both in diakinesis and metaphase I.

Material and methods

This study covers the two-rowed Markela, Karan, Alpha, Origa and Deyster varieties of Winter barley as well as the six-rowed Hemus, Potok and Rojen varieties. The fixed ears were treated by the standard acetocarmine methods. The detailed determination of bivalent configurations - closed and open ring bivalents and rod bivalents was made in diakinesis and 
metaphase I. The presence of underdeveloped chromosomes and chromosome bridges in anaphase $I$ and the number of micronuclei in tetrads were determined.

Vitality of pollen grains was defined by the degree of acetocarmine staining and the presence of 2 sperm cells and a vegetative nucleus.

\section{Results and discussion}

Normally in the phase of diakinesis one nucleolus was observed only. In single cells of Karan and Origa varieties 2 nucleoli were found. These results have shown that the nucleolus is, most provably, the product of the joint activity of two pairs of nucleolar chromosomes.

As seen on Table 1 in diakinesis seven bivalents were found to group in the following configurations: 7 closed, 6 closed +1 open, 5 closed +2 open. In that stage $19.30 \%$ to $66.67 \%$ of studied cells contained one open ring bivalent each. A considerably lower quantity-from $4.58 \%$ to $28.13 \%$ of cells contained two open ring bivalents each (Fig. 1. a, b).

In most of the cells the nucleolus was related to open ring bivalents and it justified the assumption that the open ring bivalents were formed predominantly by the nucleolar chromosomes. Stuructural or other reasons had led to the earliest termination of one chiasma in the bivalents of these chromosomes.

In metaphase I the configuration of bivalents changed with the appearance of rod bivalents formed by the open ring bivalents in diakinesis (Fig. 2. a, b). In this meiotic stage only one rod bivalent was found in all varieties and the quantity of cells varied from $38.56 \%$ to $46.07 \%$, while two rod bivalents were found in $8.52 \%$ of Karan variety cells to reach $23.41 \%$ in Hemus variety. In metaphase I the rod bivalents determined in the investigated cells totalled $49.15 \%$ to $66.55 \%$. The reduction compared to open bivalents in diakinesis is due to the presence of a certain amount of cells containing 3 rod bivalents each (Table 2).

Table 1. Analysis of bivalent configurations in diakinesis

\begin{tabular}{lcccc}
\hline \hline Variety & No. of cells & $\begin{array}{c}7 \text { closed } \\
\text { bivalents in } \%\end{array}$ & $\begin{array}{c}6 \text { closed }+1 \text { open } \\
\text { bivalents in } \%\end{array}$ & $\begin{array}{c}5 \text { closed }+2 \text { open } \\
\text { bivalents in } \%\end{array}$ \\
\hline Markela & 111 & 18.92 & 66.67 & 14.41 \\
Karan & 73 & 47.95 & 41.09 & 10.96 \\
Alpha & 59 & 37.27 & 49.15 & 13.56 \\
Origa & 64 & 18.75 & 51.56 & 28.13 \\
Deyster & 131 & 48.86 & 46.56 & 4.58 \\
Hemus & 141 & 40.40 & 46.80 & 12.00 \\
Potok & 59 & 33.90 & 35.59 & 22.03 \\
Rojen & 57 & 71.93 & 19.30 & 7.02 \\
\hline
\end{tabular}

Table 2. Analysis of bivalent configurations in metaphase I

\begin{tabular}{lcccr}
\hline Variety & No. of cells & $\begin{array}{c}7 \text { closed } \\
\text { bivalents in } \%\end{array}$ & $\begin{array}{c}6 \text { closed }+1 \text { open } \\
\text { bivalents in } \%\end{array}$ & $\begin{array}{c}5 \text { closed }+2 \text { open } \\
\text { bivalents in } \%\end{array}$ \\
\hline Markela & 236 & 50.00 & 38.56 & 10.59 \\
Karan & 223 & 49.94 & 40.81 & 8.52 \\
Alpha & 356 & 40.73 & 39.61 & 17.41 \\
Origa & 267 & 29.96 & 46.07 & 19.48 \\
Deyster & 265 & 42.26 & 42.26 & 12.84 \\
Hemus & 299 & 33.78 & 39.13 & 23.41 \\
Potok & 254 & 46.06 & 40.94 & 10.64 \\
Rojen & 165 & 41.21 & 41.82 & 14.54 \\
\hline
\end{tabular}




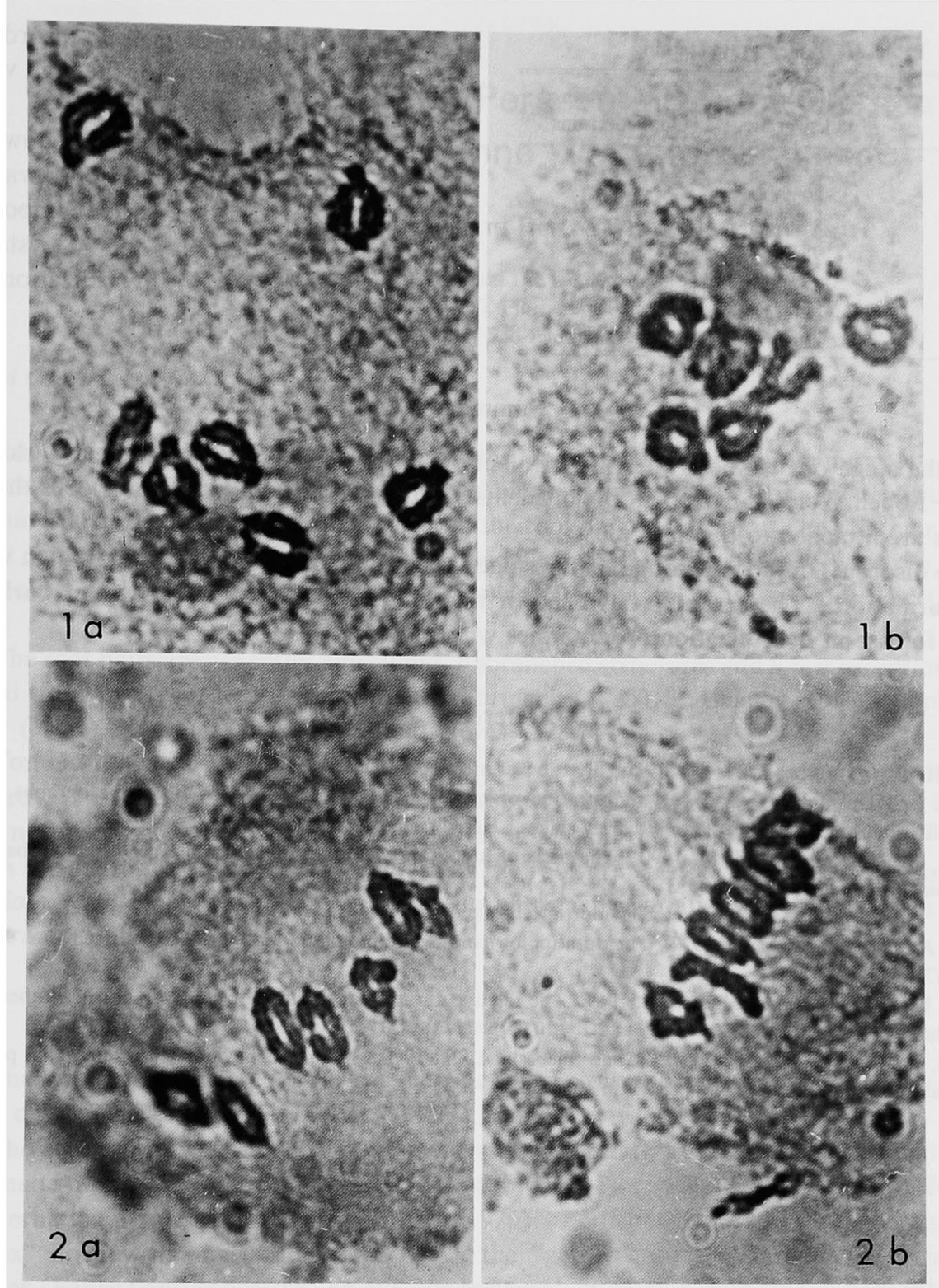

Figs. 1-2. 1. Bivalent configurations in diakinesis: 1a) 7 closed ring bivalents; 1b) 6 closed +1 open ring bivalents. 2. Bivalent configurations in metaphase I: 2a) 7 closed ring bivalents; 2b) 6 closed +1 rod bivalents.

Two univalents were found in single cells of Markela, Alpha, Deyster, Hemus, Potok and Rojen varieties.

The next meiotic stage - anaphase I-ran almost unperturbed. Underdeveloped chromosomes or chromosome bridges were observed in $0.50 \%$ to $2.20 \%$ of the investigated cells of Origa or Karan varieties respectively. About 5\% of the cells of Alpha variety had abnormalities in that stage.

In the concluding stage of meiosis - telophase II-the defects were quite few. One micronucleus formed of underdeveloped chromosomes in anaphase I was discovered in single tetrads. No pentads were observed. 
Table 3. Pollen grain staining

\begin{tabular}{lcc}
\hline \hline Variety & $\begin{array}{c}\text { \% of stained } \\
\text { pollen grains }\end{array}$ & $\begin{array}{c}\text { \% of unstained } \\
\text { pollen grains }\end{array}$ \\
\hline Markela & 92.84 & 7.16 \\
Origa & 89.43 & 10.57 \\
Deyster & 89.67 & 10.33 \\
Karan & 95.23 & 4.77 \\
Rojen & 93.95 & 6.05 \\
Hemus & 95.53 & 4.47 \\
Potok & 96.23 & 3.77 \\
\hline
\end{tabular}

The low degree of meiotic disorders in telophase II is the reason for the high vitality pollen grains formed (Table 3 ).

The results in the table show that Karan, Rojen, Hemus and Potok varieties are suitable to be used as father components, while Markela, Origa and Deyster-as mother components in hybridization programs with other cereals.

\section{Summary}

In the stage of diakinesis the ring bivalents form 3 types of configurations -7 closed, 6 closed +1 open, 5 closed +2 open ring bivalents. In the majority of investigated cells the open bivalents are attached to the nucleolus.

The disorders in the following meiotic stages are insignificant thus resulting in high vitality pollen formation. These results have shown that the studied varieties of winter barley are suitable for use in hybridization programmes with other cereals.

\section{References}

Bennett, M. D. and Finch, R. A. 1971. The duration of meiosis in barley. Genet. Res. 17: $209-214$.

Ekberg, I. and Eriksson, G. 1965. Demonstration of meiosis and pollen mitosis by photomicrographs and the distribution of meiotic stages in barley spikes. Hereditas 53: 127-136.

Evans, G. M. and Rahman, M. M. 1990. The basis of low grain yield and infertility in autotetraploid barley $(H$. vulgare). Heredity 64: 305-314.

Fedak, G. 1975. Fertility and meiotic behaviour in tetraploid barley. Can. J. Genet. Cytol. 17: 121-123.

Finch, R. A. and Bennett, M. D. 1972. The duration of meiosis in diploid and autotetraploid barley. Can. J. Genet. Cytol. 14: 507-515.

Lindgren, D., Eriksson, G. and Ekberg, I. 1969. The relative duration of the meiotic stages in pollen mother cells of barley. Hereditas 63: 205-212.

Reinbergs, E., Kao, K. N., Harvey, B. Z. and Shebeski, L. H. 1970. Meiotic behaviour and preferential pairing in autotetraploid barley. Crop Sci. 10: 569-571. 